\title{
High School Students' Use of Digital General Resources During Lockdown
}

\author{
Alice Lemmo ${ }^{1 *}$ (D), Andrea Maffia ${ }^{2}$ (D) \\ 1 University of L'Aquila, ITALY \\ 2 University of Pavia, ITALY \\ * Corresponding author: alice.lemmo@univaq.it
}

Received: 19 Jul. 2021 Accepted: 11 Dec. 2021

Citation: Lemmo, A., \& Maffia, A. (2022). High School Students' Use of Digital General Resources During Lockdown. European Journal of Science and Mathematics Education, 10(1), 139-153. https://doi.org/10.30935/scimath/11465

\begin{abstract}
:
There is not a large body of literature about digital resources found and accessed autonomously by high school students while studying mathematics, whereas this topic has become more and more relevant in times of lockdown due to the pandemic. Italy has been one of the first countries facing lockdown for an extended time, making this country a paradigmatic example: in this paper we investigate what kind of digital resources are accessed by the Italians high school students who actually use them and why. According to our results, students' aims and expectations vary according to the school grade, but are not as much devoted to procedural learning as previous literature has shown. Also, we observe that the type of searched media (text, video, image, etc.) is related to the mathematical contents and to students' objectives. Keywords: COVID-19, digital resources, general resources, high school
\end{abstract}

\section{INTRODUCTION}

Pepin and Gueudet (2018) distinguish between curriculum resources as resources proposed to students and aligned with the course curriculum and general resources which students might find/access autonomously on the web. Curriculum resources are developed, proposed by teachers and used by students for the learning of the mathematics course, inside and outside the classroom; general resources are the non-curricular material resources mobilized by students, such as general websites (e.g. Wikipedia, YouTube, etc.).

There is a wide literature about the use of digital curriculum resources in mathematics education, comprehending studies about the design of digital resources, teachers' use of digital resources, and students' interactions with digital resources during classes (Pepin et al., 2017). However, literature about general resources and, more specifically, concerning which types of resources are selected autonomously by students and why is much rarer (Muir, 2014; Nì Shé et al., 2017; van de Sande et al., 2014).

Muir (2014) shows that the use of search engines and videos retrieved online is more diffused between older students (grade 9 in her case) when compared to younger ones (grade 5 to 8 ). Both Weinberg et al. (2012) and Nì Shé et al. (2014) find undergraduate students to prefer notes and textbooks as main resources for studying mathematics, even if there are studies attesting regular use of videos and other digital general resources (e.g. Pepin \& Kock, 2019). Similar results are found in high school (van de Sande et al., 2014), but studies on this particular school grades are infrequent and the few available ones show different results than those concerning undergraduate students. For instance, answering to the 
questionnaire by Nì Shé et al. (2014), over 50\% of undergraduate students declared to access freely available online resources, such as websites and videos, while this is not the case for high school students interviewed by van de Sande et al. (2014).

The recent educational emergency raised by lockdowns caused by the pandemic may have changed considerably high school students' relationship with digital resources. As stated by Pepin (2020, p. 19):

\begin{abstract}
"the whole world is plagued by the COVID-19 pandemic, also changing policy makers' and teachers' perceptions of how education should be designed and provided. Moreover, it has changed students' perceptions of how to learn and study, and which resources to beneficially use for their learning. Certainly, since COVID19, education has been expected to be provided mainly 'at the distance', via the internet, and technology will play a major role in how education will be provided in the future."
\end{abstract}

During the period of lockdown, many high school students have been forced to study from their houses, accessing digital resources. Research shows that high school students prefer to ask help from their peers or their teachers (van de Sande et al., 2014), while parents feel themselves as less adequate in providing support with homeworks (Hoover-Dempsey et al., 2001; Muir, 2014) then it might be rare that high school resorted to their partens' help during lockdown. The number and type of resources may have changed during the pandemic time since "educators invent new educational games. Some publishers have made their curricula available online, for free, including accompanying educational software. Curricular authors have redesigned learning activities so as to explain the relation of the current pandemic and exponential coefficients in mathematical models" (Bakker \& Wagner, 2020, p.4). This specific historical time appears to be of particular interest for studying which kind of general resources high school students used, about which mathematical contents, and with what purpose.

All the literature cited till now refers mainly to countries having English as official language and the studied digital resources are usually in English, as Mathletics and KhanAcademy in the study by Muir (2014) or FreeMathHelp, Math Nerds, Math Help Forum, and several other ones in the study by van de Sande et al. (2014); little is known about non-English language general digital resources since most of the studies on this topic involve English-speaking countries. The COVID-19 emergency is a pandemic one, affecting severely many countries in which mathematics is not taught in English. In this paper we present a survey conducted in Italy and it serves as paradigmatic example of a country where the lockdown was particularly long and severe.

Italian students stopped going to school because of the COVID-19 crisis in the very first days of March 2020 and met their teacher occasionally using digital communication technologies till the end of the school year in June 2020. We administered a questionnaire during the last weeks of the three months of lockdown to Italian students using digital resources with the aim of understanding how and with which aim these students have used general digital resources for mathematics.

\title{
MATERIALS AND METHOD
}

\section{Questionnaire}

There are many and different methodologies to investigate this issue. Since our research was carried out during the COVID-19 emergency period, choosing research methodologies that include direct observations and interviews was not possible. For this reason, we opted for administering a questionnaire via web. During the emergency lockdown, the large majority of Italian schools had access to Google tools for distance activities and used them frequently (INDIRE, 2020). Then, we use Google Forms because it is quite simple and familiar for many students.

Research based on the use of a questionnaire opens several challenges: the first is about the question format. There are different reasons for using open-ended or close-ended questions (Cohen et al., 2007): 
one allows discovering the spontaneous responses given by individuals, the other avoids the bias that could arise from suggesting responses to individuals. Reja et al. (2003) highlight that there are differences between question forms: open-ended questions produce more missing data than closeended ones. However, the open-ended questions produce a more diverse set of answers. The variety of possible answers coming from open-ended questions is a richness, but such answers may result from misunderstandings of the questions. These authors suggest that open-ended questions should be more explicit in their wording than close-ended questions, which are more specified with given response alternatives (ibidem). Our goal is to collect answers from students avoiding missing answers or misunderstandings (due to the inability to do further interviews). For this reason, we chose the closeended form.

Designing closed-ended questions imposes the problem of developing both the questions and the answer options. Since literature is lacking a framework to categorize digital general resources in terms of specific mathematical contents and in terms of aims for which the resources are used, we base our characterization on the Third International Mathematics and Science Study (TIMSS) model for curriculum analysis (Robitaille et al., 1993; Valverde et al., 2002). This model provides the theoretical foundations needed to build a robust model for the analysis of mathematics and science curriculum resources and we consider that the proposed categorization applies also to the general resources that students use to complement other curriculum resources. This is in line with Robitaille et al.'s (1993, p. 43) claim:

\footnotetext{
"Any piece of curriculum so conceived-whether intended, implemented, or attained, whether a test item, a paragraph in an "official" curriculum guide, or a block of material in a student textbook-may be characterized in terms of three parameters: subject-matter content, performance expectations, and perspectives or context."
}

We adopt the TIMSS model as presented by Valverde et al. (2002). This framework is multi-layered and consists in three dimensions (Figure 1): content (subject matter topic), performance expectation (what students were expected to do with particular content) and perspective (any overarching orientation to the subject matter and its place among the disciplines and in the everyday world). Hence, the proposed dimensions are suitable for the aims of our research as we posed them in the previous section. For each dimension, we combined the list of topics proposed by TIMSS with the Italian national standards. However, digital general resources differ from textbooks: we need an additional dimension, that is the choice of the communication medium in which the information provided by the resource is received. We chose to investigate this additional dimension considering the media investigated in previous research (e.g. van de Sande et al., 2014): "Written text", "Video", "Image, Map/scheme", "Community/Social network", "Game/Videogame", "Other". Table 1 shows all categories identified by us for each dimension.

\section{MATHEMATICS}

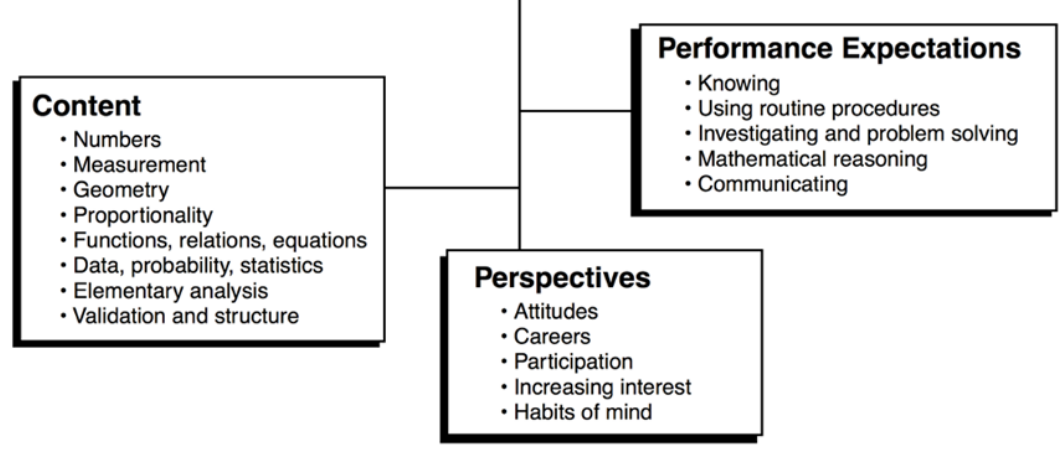

Figure 1. Diagram of multi-layered framework presented by Valverde et al. (2002) 
Table 1. List of topics for each considered dimension

\begin{tabular}{|c|c|c|}
\hline \multicolumn{3}{|l|}{ Contents } \\
\hline Numbers and operations & Measures & $\begin{array}{l}\text { Triangles, quadrilaterals, other polygons, } \\
\text { and circle }\end{array}$ \\
\hline Solid geometry & Proportionality & $\begin{array}{l}\text { Equations, inequalities, and systems of } \\
\text { equations }\end{array}$ \\
\hline Statistics & Probability & Analytic geometry \\
\hline $\begin{array}{l}\text { Study of a function, limits, and } \\
\text { derivatives }\end{array}$ & Integrals & Series and sequences \\
\hline \multicolumn{3}{|l|}{ Logic } \\
\hline \multicolumn{3}{|l|}{ Performance expectation } \\
\hline Worked examples & Exercises and tasks & Definitions and properties \\
\hline Problem solving & Proofs & Terminology and notations \\
\hline \multicolumn{3}{|l|}{ Perspectives } \\
\hline Passing the next written or oral exam & $\begin{array}{l}\text { More interesting, fun, or stimulating } \\
\text { exercises }\end{array}$ & $\begin{array}{l}\text { Understand mathematics in the following } \\
\text { school grades }\end{array}$ \\
\hline Mathematics applications & Improve reasoning & \\
\hline \multicolumn{3}{|l|}{ Media } \\
\hline Written text & Video & Image \\
\hline Map/Scheme & Community/Social network & Game/Videogame \\
\hline Other & & \\
\hline
\end{tabular}

As we discuss in the last section of this paper, we are aware that respondents' interpretation of some topics may differ. For instance, some topics could overlap and for this reason we allowed the selection of more than one answer-option. In addition, we are aware that the difference between the topics in Performance expectations could be not shared among our responders. We consider this limit acceptable because of the exploratory nature of this study. We added to the questionnaire some supplemental questions about background information (school grade and curricula) aimed at better describe the sample of students involved. The whole questionnaire is showed in Annex.

Framing our research problem within this framework we can state our research question as follows: what kind of contents and media are looked for by students accessing online general digital resources, and with what expectations and perspectives do they look for them?

\section{Sample}

Our research interest is to investigate how digital general resources are used by those students who actually (not just potentially) look for them. For this reason, to select our sample, we started directly from web sites and social networks by posting the advertisement of our survey. Then, our sample is a convenience sample. We selected those web pages that first appear in a Google and Facebook search, regardless of any judgement on the quality of the offered materials and resources. We looked for Facebook Italian groups in which people ask/provide help for mathematics; we published a post containing the link to our questionnaire. Also, we search on Google for Italian websites providing digital resources for mathematics, then we reached the managers by email asking to put an announcement of our questionnaire together with a link. Four websites ${ }^{1}$ responded positively to our request. Then our announcements could be seen by those that were already visiting dedicated communities or websites: the sample itself is already formed by students who usually use the web and are possibly the most active in terms of the digital.

Students, teachers, tutors at all school grades answered. We selected all respondents who identified themselves as high school students. The sample is composed by $\mathrm{N}=113$ students. In Table 2 there is the distribution of the sample according to grades and school curricula.

\footnotetext{
${ }^{1}$ www.webtutordimatematica.it - www.matelezioni.info - www.matematika.it - www.lezionidimatematica.net
} 
Table 2. Sample of students by grades and school curricula

\begin{tabular}{|c|c|c|c|c|c|c|}
\hline & Grade & $\begin{array}{c}\text { Scientific high } \\
\text { school }\end{array}$ & $\begin{array}{c}\text { Other high } \\
\text { schools }\end{array}$ & $\begin{array}{l}\text { Technical } \\
\text { institutes }\end{array}$ & $\begin{array}{c}\text { Vocational } \\
\text { schools }\end{array}$ & Total \\
\hline \multirow[t]{2}{*}{ First two years } & G09 & 18 & 3 & 2 & 3 & 26 \\
\hline & G10 & 25 & 5 & 3 & 0 & 33 \\
\hline \multirow[t]{2}{*}{ Second two years } & G11 & 25 & 1 & 3 & 1 & 30 \\
\hline & G12 & 9 & 2 & 1 & 0 & 12 \\
\hline \multirow{2}{*}{$\begin{array}{l}\text { Last year } \\
\\
\text { Total }\end{array}$} & G13 & 6 & 1 & 4 & 1 & 12 \\
\hline & & 83 & 12 & 13 & 5 & 113 \\
\hline
\end{tabular}

In Italy, high schools include students from grade 9 to grade 13, we divided the sample into categories of grades and type of school due to the structure of the Italian secondary school system. Indeed, there are three secondary school curricula: high school (liceo), technical institutes and vocational schools. The high school courses provide students with the cultural and methodological tools for an in-depth understanding of reality. At the end of these courses, students should deal with situations, phenomena, and problems with a rational, creative, and critical attitude; they also should acquire knowledge, skills and competences consistent with their personal abilities and choices and suitable for further studies of higher education. In particular, scientific high schools focus on scientific subjects such as Mathematics, Physics, Biology, and so on. The technical institutes, on the other hand, propose directions related to sectors that are linked with works in the economic and productive fields. Finally, vocational schools train students in arts, crafts, and professions.

In our sample, students from scientific high schools are in the highest percentage (more than $70 \%$ ). This might suggest that most students looking for digital mathematics resources attend this type of school. This might depend on the fact that the number of hours dedicated to mathematics are much higher than in other school curricula. Also, scientific high school mathematics curriculum is wider: mathematical contents like sequences and differential equations are taught in this kind of schools and not in the other curricula.

Italian standards for high schools set the goals for the development of competences, knowledge, and skills in all disciplines for groups of years: first two years (grades 9 and 10), second two years (grades 11 and 12) and last year (grade 13). For this reason, our results will be presented dividing students in these groups.

\section{RESULTS}

We discuss the data collected by the questionnaire by dimensions. The data is represented as a percentage (the sum of the percentages is greater than 100 because each student could choose more than one option).

\section{Contents}

In the diagram presented in Figure 2, the students' choices for the content dimension are represented. About $50 \%$ of students choose "Equations, inequalities and systems". It is selected by students in all school grades. In particular, $60 \%$ of grade 9 and 10 students and 30\% in grades 11, 12, and 13 chose this option. It is also the most selected topic between all school curricula. This aspect is interesting but not surprising, because it is one of the topics of Algebra that finds several applications in all areas of mathematics curricula. For example, equations and inequalities are useful tools to study Analytical geometry, functions, etc. This assumption can be confirmed by the fact that $75 \%$ of students who chose this topic select at least one other topic. "Analytical geometry" (44\% of students who selected "Equations...") and "Polygons and circle" (33\% of students who selected "Equations...") are often selected together with "Equations, ...." and are also the second and third most popular topics. Besides "Equations, inequalities and system", there are other topics selected by students of all grades: "Measures", "Statistics", "Probability", "Limits, derivatives and study of a function" and "Logic". This may suggest that there are topics that are not strictly related to school grades. The interesting fact about 


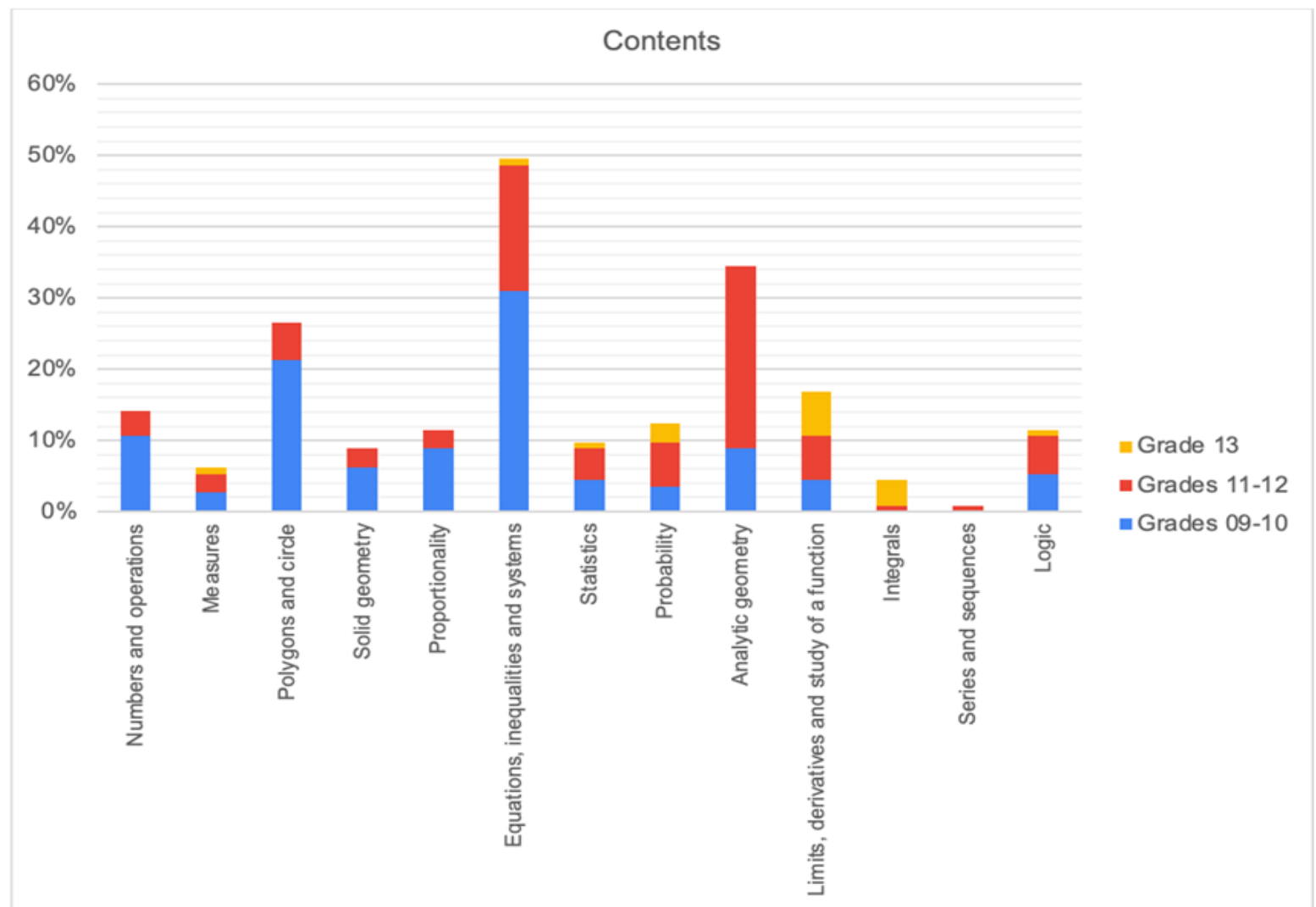

Figure 2. Students' choices within the "Content" dimension

these topics is that they are all chosen at least with one other topic. For example, among students who choose "Measures", only one student does not select any other topic: $87.5 \%$ of them choses "Equations, inequalities and systems", 75\% of them selects "Numbers and operations" and the same percentage choses "Proportionality". This outcome could suggest that students see these topics as more strictly linked to other topics.

On the contrary, there are some topics that appear related to specific grades: some contents are not of interest to higher grades students and vice versa there are others that are not relevant to lower grades students. For example, the contents strictly linked to the geometric field are chosen by students in the first 4 years of high school, while those related to Calculus are selected by students of the last 3 years. Topics that distinguish different school grades are rarely selected together with other topics or they are groups with few other topics. For example, "Analytic geometry" is mainly selected with "Equations, inequalities, and systems" (64\%) and "Polygons and circle" (36\%); only a quarter of the students who select "Analytic geometry" pick other topics different by the previous two.

This is not surprising since, in the Italian national standards, synthetic and analytical Geometry are relevant in the first three years of high school, while Calculus is a prevailing topic of the last years. Muir (2014) shows that most of the students of her online survey look for concepts or topics that are covered in class; in our results it appears that internet resources are used as a way to follow this up. This hypothesis is also confirmed by the analysis of Perspectives (see below): most students declare that they are looking for digital resources in order to pass the next examination.

\section{Performance Expectations}

Figure 3 represents students' choices for the Performance Expectations dimension. "Definition and properties" is the most popular topic for students of all grades and school curricula, while "Problem solving" seems to catch a lower interest in our sample. 


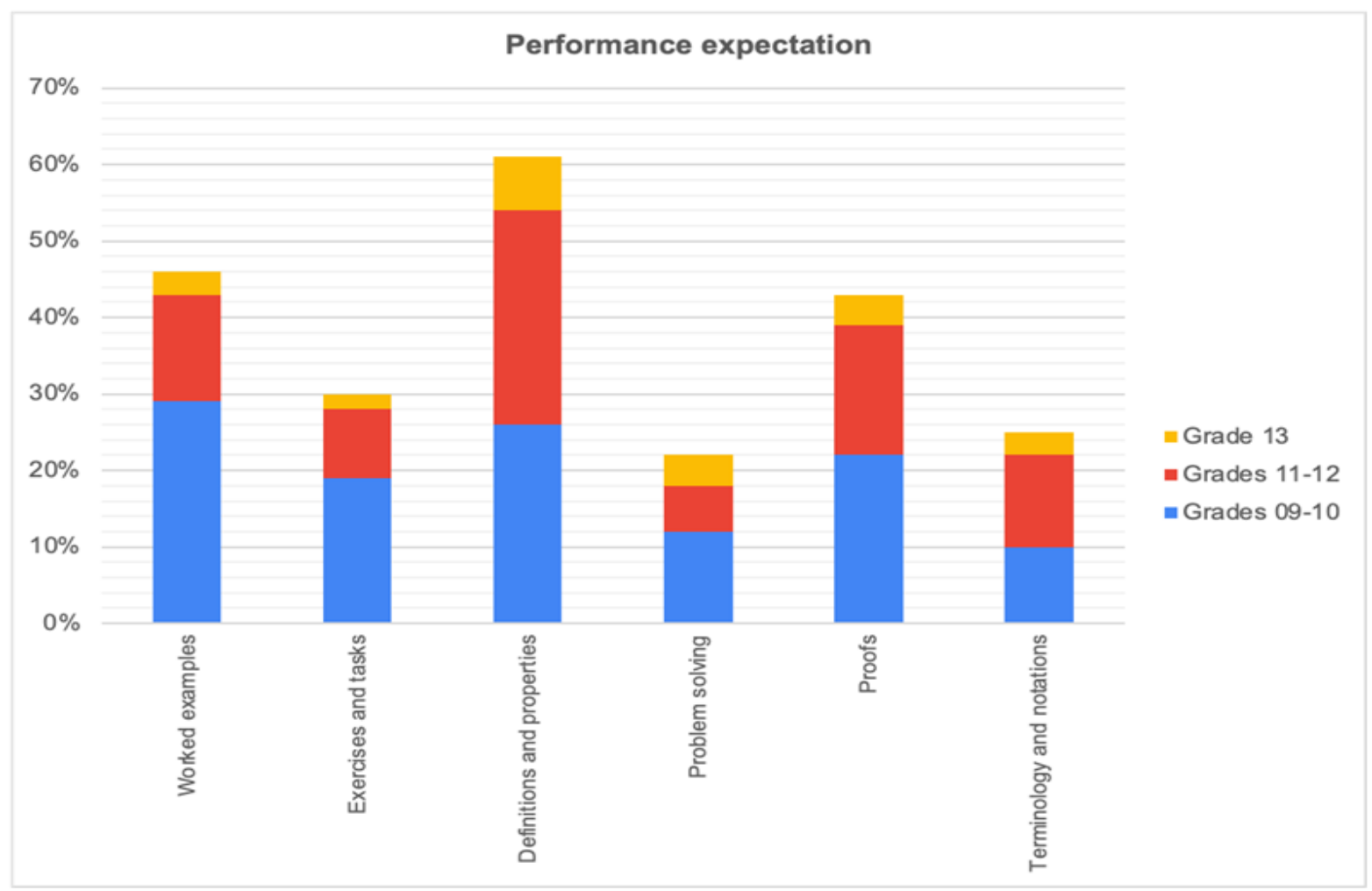

Figure 3. Students' choices within the "Performance Expectation" dimension

The relationships between the topics are very interesting: for example, it seems that there is a close relationship between "Definition and properties" and "Terminology and notation". Among students who select "Terminology and notation" only two students do not choose "Definition and properties" as well. Since $35 \%$ of students who choose "Definitions and properties" do not choose "Terminology and notation", we suppose that "Terminology and notation" could be a sort of subset of "Definition and properties". We could make a similar hypothesis for "Proofs": 71\% of students who select this topic, select also "Definition and properties", other topics are chosen in very little percentages.

Students who select "Problem solving", "Exercises and tasks" and "Worked examples" choose the other topics with quite similar percentages. It may therefore seem that students who are looking for "Terminology and notations" and "Proofs" are more inclined to other resources related to more theoretical topics ("Definitions and properties") while those who choose exercises and problems look with similar percentages for all the other topics of Performance expectations.

We can note that all topics of this dimension are chosen by at least $20 \%$ of students of our sample (unlike in other dimensions where there are topics selected by a percentage of students below $10 \%$ ) but the frequency of their choices is different according to students' grades. Some topics are chosen by similar percentages of students: for instance, "Definitions and properties" are selected by about $70 \%$ of students of each grade. In contrast, "Worked examples" and "Exercises and tasks" drop from about $60 \%$ of choices in grades 9 and 10 to less than $20 \%$ in grade 13 . We can conjecture that in upper school grades students feel less the need to be guided in the solution of exercises or to practice with new and different tasks but rather seek more theoretical aspects such as definitions and proofs.

\section{Perspectives}

There is a little literature about students' expectations and aims when resorting to digital resources. Muir (2014, p. 844) registered, through interviews, several different answers comprehending "when we have a maths test coming up" and "if I struggle on one of the aspects that we're doing". Our categories - based on TIMSS framework's categorization of Perspectives - were all chosen by the students in our 


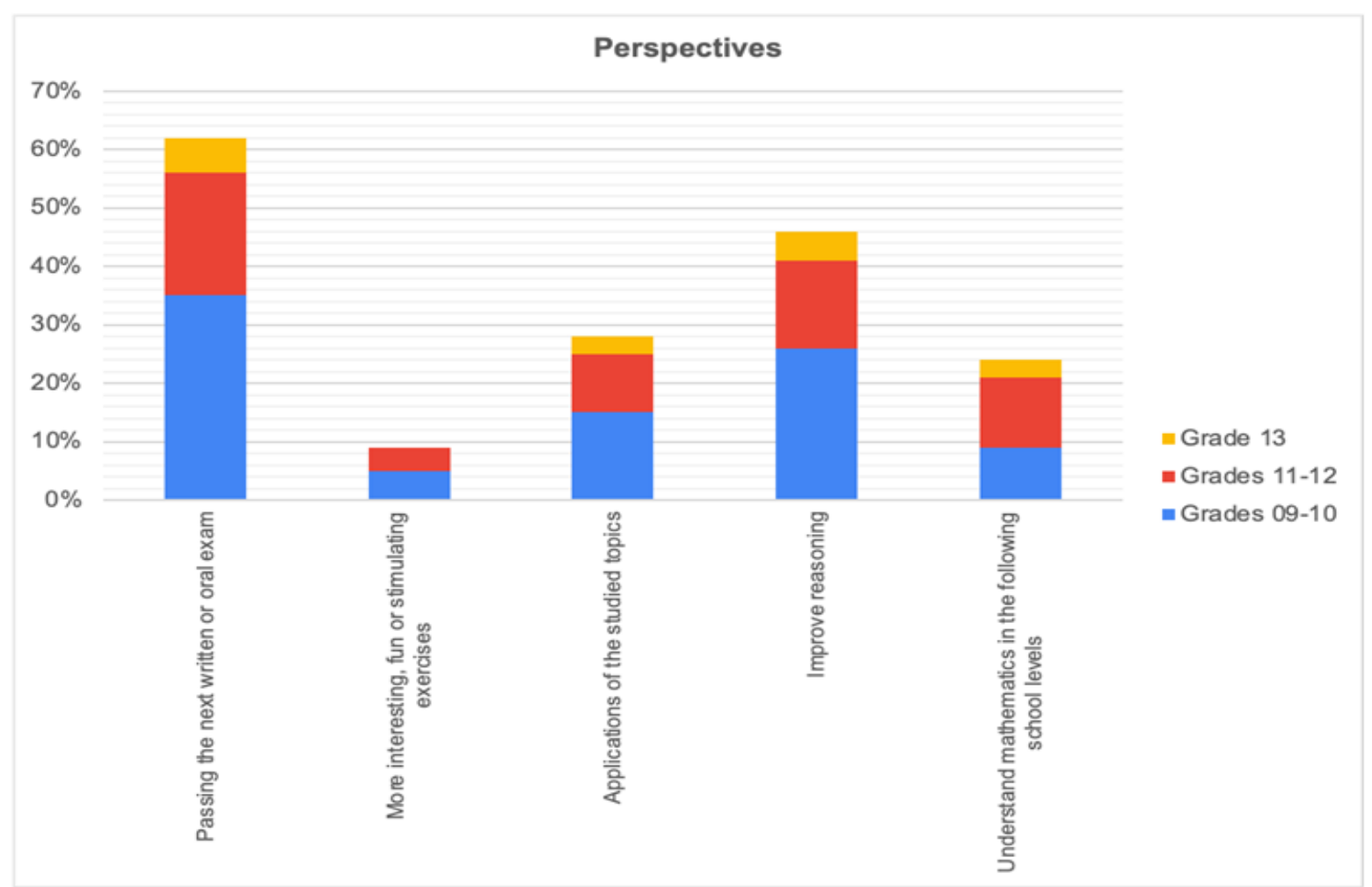

Figure 4. Students' choices within the "Perspective" dimension

sample (Figure 4). Differences in frequency of selection are high, but they apparently do not depend significantly on the school grade. Over $60 \%$ of the students have used digital resources to get prepared for an examination (oral or written). Half of these students look for "Worked examples", while two thirds of them look for "Definitions and properties"; this suggests that most procedural knowledge is privileged, as already observed by Muir (2014) and Weinberg et al. (2012). This might depend on the fact that examinations are more procedural than conceptual; another possible interpretation is that the available digital resources do not emphasize conceptual learning. However, we can observe that the percentage of students resorting to digital resources to improve their reasoning is quite high $(46 \%)$ and $25 \%$ of the whole sample selects both "Passing the next exam" and "Improving reasoning", so suggesting that - at least for these students - reasoning may be important for passing the examinations. Seeking for applications, more interesting exercises, or understanding mathematics in next school years are less selected, but not absent.

Considering the type of school curriculum, students from the scientific high schools reflect the choices of the sample (also because it mostly consists of them) but it is interesting to note that more than half of the other students (e.g. from technical or vocational schools) choose "Passing the next written or oral exam" and about $30 \%$ of them select "Understand mathematics in the following school levels". Therefore, most of the students who choose "Improve reasoning" attend the scientific high school while the other students seem to prefer to explore mathematics in the following grades/levels.

\section{Media}

Previous research shows that students rely mainly on notes and websites for their individual studying (Nì Shé et al., 2017). Consistently, we can observe that "Written texts" are the main searched resource by our sample of students, and almost one third of the sample selects only this option (Figure 5). We can notice that digital written texts may be very different from the usual notes taken in class or given by the teachers. Indeed, as observed by Kraidy (2002), digital text contains hyperlinks allowing nonlinear consultation of the material. 


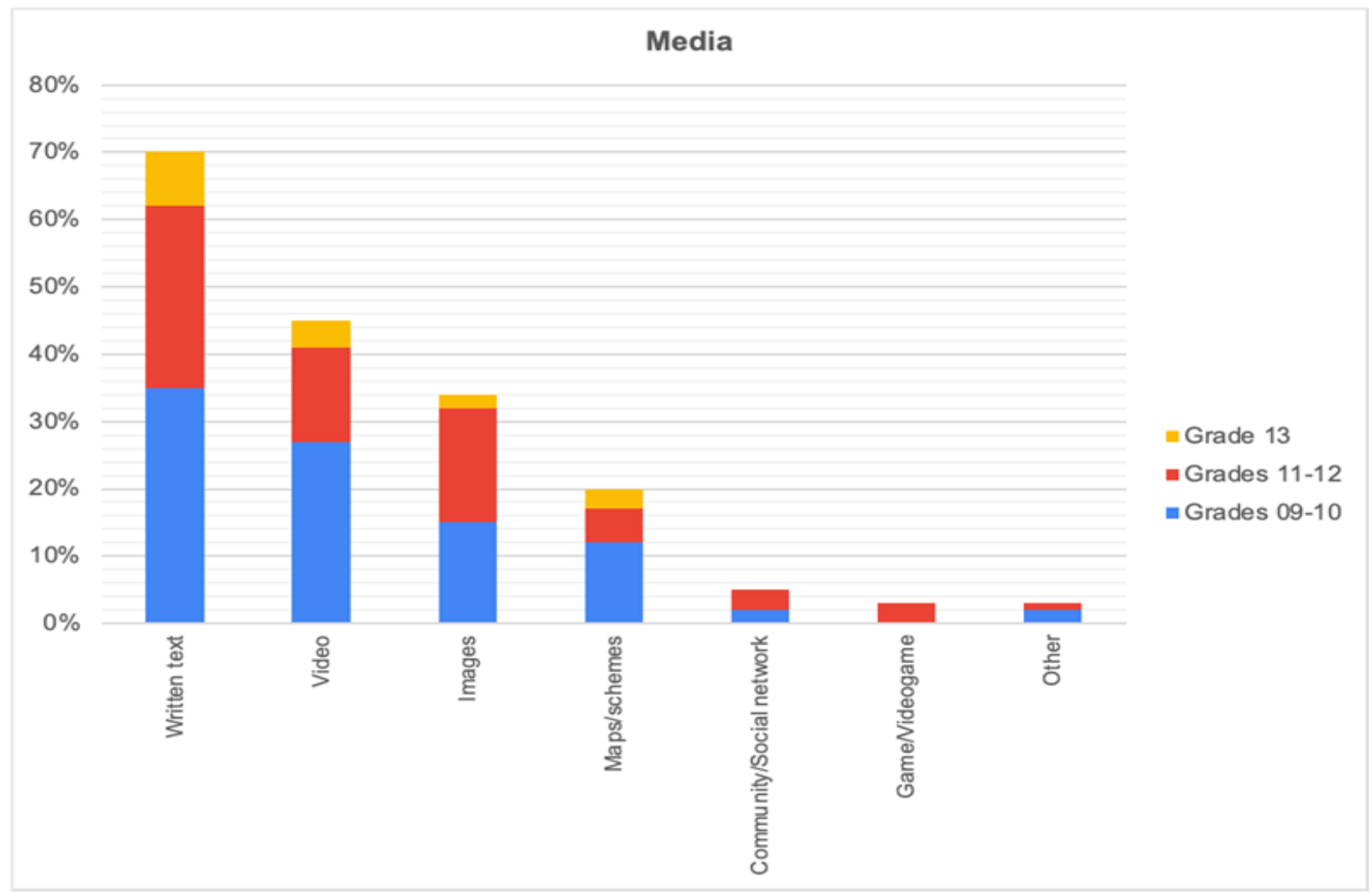

Figure 5. Students' choices within the "Media" dimension

Almost half of the students look for videos as well. This percentage is higher than what Nì Shé et al. (2017) found for college students, while it is consistent with the results obtained by Muir (2014) for grade 9 students. We can state that studying from videos has been a widespread activity during the lockdown period, especially among grade 9 and 10 students, but it may as widespread as it was before. This fact should raise our attention since learning realized by students using regularly videos has been observed to be superficial by Trenholm et al. (2019), even if contrasting results have been obtained in other studies (e.g. Yoon \& Sneddon, 2011): Pepin and Kock (2019) studied a case of a student using YouTube purposely for enhancing her conceptual understanding. We can observe differences according to the different schools' curricula: one third of the students from technical or vocational schools prefer "Maps/Schemes" while scientific high school students prefer "Video" and "Images".

Social networks, communities, games and other media are selected by a very small number of students. Using Choppin et al.'s (2014) terminology we can state that resources with high interactivity and opportunities for socializing were less used by Italian high school students during lockdown. This may depend on the fact that those resources are not well known or are considered less credible (Muir, 2014). Another possible interpretation is that students resort individually only to the same digital resources that were already introduced at school - and these resources do not usually include social networks and other online communities.

\section{Crossing Dimensions}

While the referred dimensions already give us a picture of what resources and why were looked for by Italian students, by referring to these four dimensions we can cross the analysis to understand the relations between the answers provided in the various parts of the questionnaire. For instance, Performance expectations data are interesting when compared with the content choices: "Definitions and properties" is mainly associated to the choice of "Equations, inequalities and systems" (53.6\%), "Polygons and circle" (27.5\%) and "Analytical geometry" (45\%), whereas "Problem solving" is chosen independently from the content dimension. This evidence can suggest that performance expectations in teaching and learning may vary depending on the mathematical content (as already observed in other 
contexts by Kieran, 2013); this interpretation appears reasonable assuming that students look for resources related to what they experienced in the classroom (Muir, 2014). A different interpretation of the phenomenon could be due to the fact that the digital resources selected for this study often fail to cover all the dimensions studied in this survey.

Curiously, there seems to be a relation between these Perspectives and the selected Media as well. Most of the students looking for digital resources to pass the next exam, look for "Written texts". On the contrary, the percentage of students looking for "Videos" is almost equal to that of "Written texts" when the aim is that of knowing more about next school years or improving reasoning. Among the students who look for "Videos", the percentage of those aiming to "Pass the next exam" is almost the same of those who want to "Improve reasoning" (almost 30\% of the sample in both cases). On the contrary, the students selecting "Written text" and "Passing the next exam" are $45 \%$ of the sample, while only $32 \%$ of the students select both "Written text" and "Improve reasoning".

Around one third of the sample declared that they look for images, and a high percentage of these students are attending grade 11 or 12. Surprisingly, students do not look for images only in the geometrical contents: $19.5 \%$ of the students in the sample selected "Image" as the searched Media, and also "Equations..." as content. Possibly, students look for images of worked examples for the solution of symbolic equations. This hypothesis appears disconfirmed by an analysis of students' selection of Performances: among the students selecting "Images" as Media, the majority looks for definitions, properties, or proofs. Indeed, formulas are easily findable by using the most common images search engines.

Another interesting result is the crossing analysis between Perspectives and Performance expectations; as already pointed, the majority of students seems to be more interested in passing the next exam, and these students look for all Performance expectations topics. This does not happen for all Perspective topics, only Improving reasoning is chosen together with all Performance expectations ones. This might suggest that some students seem to be aware that in order to improve mathematical reasoning it is important to work on procedural as well as conceptual and problem-solving aspects.

\section{DISCUSSION}

Starting from the premise that there is little knowledge about the use of general resources in mathematics by high school students, we wondered how and with which aims Italian students have used digital resources for mathematics autonomously during the lockdown caused by the pandemic. In particular, considering students accessing general digital resources, we wonder to analyse what kind of contents and media are looked for and with what expectations and perspectives do they look for them. Italy appears as an interesting case for this kind of question since the lockdown has started early and has been extensive. Furthermore, most of the resources cited in literature are in English, a language that could still be not mastered by non-native speakers at high school level (INVALSI, 2019); then this study adds to the literature information about the use of general digital resources by students in a country in which English is not the main language.

Our data collection and analysis have been organized around four dimensions: Contents, Performance expectations, Perspectives, and Media. It is relevant to note that research presented in literature does not always address all these dimensions; Content is often neglected while we consider it extremely relevant for mathematics education research. Our results concerning Contents and Perspectives are in line with the study by Muir (2014) and seem to confirm that students, even when searching autonomously, look mainly for the mathematical topics that are addressed in class, and with the main aim of passing the upcoming test. These results may suggest that students use digital general resources to work on procedural rather than conceptual understanding of mathematics, as already noted by other researchers (Muir, 2014; Nì Shé et al., 2017). However, the analysis of students' answers concerning Performance expectations show that proofs are highly searched by students. In this perspective, the dimension Performance Expectations lead us to deepen the results of previous research. Indeed, it seems 
that students consider general digital resources also as tools for exploring mathematics conceptual processes such as definition and proofs. Concerning Media, we found that written texts and videos are the mainly used resources, in line with previous findings in the literature (Nì Shé et al., 2014; Pepin \& Kock, 2019; Weinberg et al., 2012), but we noticed how images can also play a relevant role. In particular, we noticed that the type of searched media can vary during high school according to the school grade, extending what Muir (2014) has noted for previous grades.

The chosen methods allow crossing the analysis of the four dimensions. In this way, we noted that different mathematical contents are associated with different perspectives: for instance, seeking for definitions and properties is highly frequent in the case of equations, plane geometry and analytic geometry, while problem solving (even if rarer) is equally selected for all the contents. Also, we noted a dependency between the chosen media and the perspective of the search: students aiming at improving reasoning are more frequent among those looking for videos when compared with those looking for written text. This is coherent with the case study by Pepin and Kock (2019) involving a student for whom the tutor and quizzes were the preferred resources for procedural understanding, while YouTube was used for conceptual understanding.

The crossed analysis of the different dimensions could be further developed, providing new opportunities for both qualitative and quantitative research. Furthermore, researching possible changes in the use of digital general resources after the pandemic would help in understanding if the results presented in this paper depends on this particular moment or will remain stable even later.

We must notice that, differently than other researchers (e.g., Muir, 2014) we did not ask questions about specific digital resources. However, our sample was constructed by advertising the questionnaire on webpages and communities appearing as first results on search engines and social networks, regardless of any judgement on the quality of the offered materials and resources. At our eyes, those resources appeared as focussing a lot on procedural aspects and rote learning rather than deep comprehension of the related mathematics. This fact may affect the obtained results, but we still consider our findings relevant since those resources are the first found by the Italian students for whom other famous resources cited in the literature are not available because of the language barriers. Also, we should consider that education about the use of digital resources appears still not completely integrated in Italian mathematics classes, despite the fact that research shows how the quality of a resource depends on the user (Trgalová \& Jahn, 2013), students in our case. Information provided by our study may help in designing teaching sequences for high school students. At the same time, teachers should be trained to help them integrating digital resources in their own teaching as mentioned by several other authors (e.g., Pepin, 2020; Trgalová \& Jahn, 2013). This is particularly relevant in the case of resources provided through the internet in the case of Italian teachers. Indeed, Tella (2011) shows how teachers' self-efficacy towards producing resources for the web decrease with their age, and Italian teachers are, on the average, among the eldest ones in the world (OECD, 2020).

Finally, we should stress that the results presented in this paper suffer from the limits of our research. First, we must consider that ours is a convenience sample and students of different grades and types of school curricula are not equally represented. Second, many of the terms used in the questionnaire may not univocally defined for students (f.i. the difference between 'exercises' and 'problem solving'), then their choosing of options might not be based on a common set of understandings; for this reason, we never contrasted results about these topics. Furthermore, the obtained results should not be considered as general but should be interpreted in the specific context in which they have been obtained. Future research on this topic may address more background variables as gender or geographical location. Anonymity of questionnaires does not allow us to contact the students for further interviews, but this kind of design may be recommended to deepen research on this topic. Being aware of the limits of the present study, we consider the results relevant because of the historical time in which the data are collected. Our instruments and methods for researching the use of digital resources are susceptible of improvement and further research on students' individual use of general digital resources for 
mathematics. They could be used as a tool to inform future development of web sites and it can help teachers know how to direct students to better websites. The presented study refers to the Italian context, but the choice of using TIMSS model for designing the questionnaire could also allow administering it to students of different countries and make comparisons.

This research provides a snapshot of a certain historical moment. The obtained results do not allow us to make assumptions or conjectures about the use of digital resources during the pandemic. By comparing them with new data collected in the future, it will be interesting to contrast different historical periods.

Author contributions: All authors were involved in concept, design, collection of data, interpretation, writing, and critically revising the article. All authors approve final version of the article.

Funding: This work was partially supported by a grant from Ministero dell'Università e della Ricerca (MIUR) (IT) (PONAIM1849353-3).

Declaration of interest: Authors declare no competing interest.

Data availability: Data generated or analysed during this study are available from the authors on request.

\section{REFERENCES}

Bakker, A., \& Wagner, D. (2020). Pandemic: Lessons for today and tomorrow? Educational Studies in Mathematics, 104, 1-4. https://doi.org/10.1007/s10649-020-09946-3

Choppin, J., Carsons, C., Bory, Z., Cerosaletti, C., \& Gillis, R. (2014). A typology for analyzing digital curricula in mathematics education. International Journal of Education in Mathematics, Science and Technology, 2(1), 11-25. https://doi.org/10.18404/ ijemst.95334

Cohen, L., Manion, L., \& Morrison, R. (2007). Research methods in education. Routledge Falmer. https://doi.org/10.4324/9780203224342

INDIRE (2020). Report integrativo Indire indagine tra i docenti Italiani: Pratiche didattiche durante il lockdown [Supplementary report Indire survey among Italian teachers: Teaching practices during the lockdown]. Firenze: Istituto Nazionale Documentazione, Innovazione, Ricerca Educativa [Florence: National Institute for Documentation, Innovation, Educational Research]. https://issuu.com/indire/docs/report_integrativo_novembre_2020_con_grafici_1_

INVALSI (2019). Rapporto prove INVALSI 2019 [INVALSI test report 2019]. INVALSI. https://www.invalsiopen.it/ risultati/rapporto-prove-nazionali-invalsi-2019/

Kieran C. (2013). The false dichotomy in mathematics education between conceptual understanding and procedural skills: An example from Algebra. In K. Leatham (Ed.) Vital directions for mathematics education research (pp. 153-171). Springer. https://doi.org/10.1007/978-1-4614-6977-3_7

Kraidy, U. (2002). Digital media and education: Cognitive impact of information visualization. Journal of Educational Media, 27(3), 95-106. https://doi.org/10.1080/1358165020270302

Muir, T. (2014). Google, Mathletics and Khan Academy: students' self-initiated use of online mathematical resources. Mathematics Education Research Journal, 26(4), 833-852. https://doi.org/10.1007/s13394-014-0128-5

Ní Shé, C., Mac an Bhaird, C., Ní Fhloinn, E., \& O'Shea, A. (2017). Students' and lecturers' views on mathematics resources. Teaching Mathematics and its Applications, 36(4), 183-199. https://doi.org/10.1093/teamat/hrw026

OECD (2020). Education at a Glance 2020: OECD indicators. OECD Publishing. https://doi.org/10.1787/27f5f9c5-en

Pepin, B. (2020). Quality of (digital) resources for curriculum innovation. In Proceedings of the 10th ERME Topic Conference MEDA 2020 (pp. 19-26). Linz (Austria). https://hal.archives-ouvertes.fr/hal-02932218

Pepin, B., \& Gueudet, G. (2018). Curriculum resources and textbooks in mathematics education. In S. Lerman (Ed.), Encyclopaedia of mathematics education (pp. 1-5). Springer International Publishing. https://doi.org/10.1007/978-3-319-73253-4_17

Pepin, B., \& Kock, J (2019). Towards a better understanding of engineering students' use and orchestration of resources: Actual student study paths. In U. T. Jankvist, M. Van den Heuvel-Panhuizen, \& M. Veldhuis, (Eds.) Proceedings of the Eleventh Congress of the European Society for Research in Mathematics Education (pp. 2614-2621). Utrecht University. https://hal.archives-ouvertes.fr/CERME11/hal-02422663v1

Pepin, B., Choppin, J., Ruthven, K., \& Sinclair, N. (2017). Digital curriculum resources in mathematics education: Foundations for change. ZDM, 49(5), 645-661. https://doi.org/10.1007/s11858-017-0879-z

Reja, U., Manfreda, K. L., Hlebec, V., \& Vehovar, V. (2003). Open-ended vs. close-ended questions in web questionnaires. Developments in Applied Statistics, 19(1), 159-177. ISBN 961-235-123-6

Robitaille, D. F., Schmidt, W. H., Raizen, S. A., McKnight, C. C., Britton, E., \& Nicol, C. (1993). TIMSS monograph No. 1: Curriculum frameworks for mathematics and science. Pacific Educational Press. ISBN-0-88865-090-6 
Tella, A. (2011). An assessment of mathematics teachers' Internet self-efficacy: Implications on teachers' delivery of mathematics instruction. International Journal of Mathematical Education in Science and Technology, 42(2), 155-174. https://doi.org/ 10.1080/0020739X.2010.519798

Trenholm, S., Hajek, B., Robinson, C. L., Chinnappan, M., Albrecht, A., \& Ashman, H. (2019). Investigating undergraduate mathematics learners' cognitive engagement with recorded lecture videos. International Journal of Mathematical Education in Science and Technology, 50(1), 3-24. https://doi.org/10.1080/0020739X.2018.1458339

Trgalova, J., \& Jahn, A.-P. (2013). Quality issue in the design and use of resources by mathematics teachers. ZDM, 45(7), 973-986. https://doi.org/10.1007/s11858-013-0525-3

Valverde, G. A., Bianchi, L. J., Wolfe, R. G., Schmidt, W. H., \& Houang, R. T. (2002). According to the book: Using TIMSS to investigate the translation of policy into practice through the world of textbooks. Springer Science \& Business Media. https://doi.org/10.1007/ 978-94-007-0844-0_8

van de Sande, C., Boggess, M., \& Hart-Weber, C. (2014). How do high school students get help on their mathematics homework? A study of digital and non-digital resource use. Journal of Computers in Mathematics and Science Teaching, 33(4), 455-483. https://www.learntechlib.org/primary/p/130326/

Weinberg, A., Wiesner, E., Benesh, B., \& Boester, T. (2012). Undergraduate students' self-reported use of mathematics textbooks. Primus, 22(2), 152-175. https://doi.org/10.1080/10511970.2010.509336

Yoon, C., \& Sneddon, J. (2011). Students' perceptions of effective use of tablet PC recorded lectures in undergraduate mathematics courses. International Journal of Mathematical Education in Science and Technology, 42(4), 425-445. https://doi.org/10.1080/ 0020739X.2010.543165 


\section{APPENDIX: Questionnaire}

\section{General Digital Resources for Mathematics}

In this period of "distance teaching and learning", mathematics teachers often ask students to work autonomously with materials sent by them or with textbooks. Perhaps, it may happen that the materials sent are not sufficient to understand the proposed topics. If you have ever felt the need to look for other resources online, we ask you to fill in the following questionnaire. We ask you to think about those materials/resources you have looked for in mathematics.

1. Are you answering as...
a. students
b. students' relative
c. tutor
d. teacher
e. other

2. The resources you looked for are for...
a. grades 1-5
b. grades 6-8
c. grades $9-13$
d. university courses

3. (only for grades $9-13$ students) Your type of school curricula is...
a. scientific high school
b. other high school
c. technical institute
d. vocational school

4. Which kind of mathematical contents did you look for resources about?
a. Numbers and operations
b. Measures
c. Polygons and circle
d. Solid geometry
e. Proportionality
f. Equations, inequalities and systems
g. Statistics
h. Probability
i. Analytic geometry
j. Limits, derivatives and study of a function
k. Integrals
1. Series and sequences
m. Logic

5. Which kind of performance expectations did you look for resources about?
a. Worked examples
b. Exercises and tasks
c. Definitions and properties
d. Problem solving
e. Proofs
f. Terminology and notations 
6. Which type of media have you looked for your resources?
a. Written text
b. Video
c. Images
d. Maps/schemes
e. Community/Social network
f. Game/Videogame
g. Other

7. With what perspectives did you look for resources?
a. Passing the next written or oral exam
b. More interesting, fun, or stimulating exercises
c. Applications of the studied topics
d. Improve reasoning
e. Understand mathematics in the following school levels 